\title{
Traduire
}

Une eutre perspective sur $r$ tatadciction

Revue française de la traduction

$241 \mid 2019$

La formation à l'honneur

\section{Shakespeare a mal aux dents, de Marie Vrinat- Nikolov et Patrick Maurus}

\section{Marie-Céline Georg}

\section{(2) OpenEdition}

1 Journals

Édition électronique

URL : http://journals.openedition.org/traduire/1904

DOI : 10.4000/traduire.1904

ISSN : 2272-9992

Éditeur

Société française des traducteurs

\section{Édition imprimée}

Date de publication : 16 décembre 2019

Pagination : 124-126

ISSN : 0395-773X

\section{Référence électronique}

Marie-Céline Georg, «Shakespeare a mal aux dents, de Marie Vrinat-Nikolov et Patrick Maurus »,

Traduire [En ligne], 241 | 2019, mis en ligne le 16 décembre 2019, consulté le 23 septembre 2020. URL : http://journals.openedition.org/traduire/1904 ; DOI : https://doi.org/10.4000/traduire.1904 


\section{Lu pour vous}

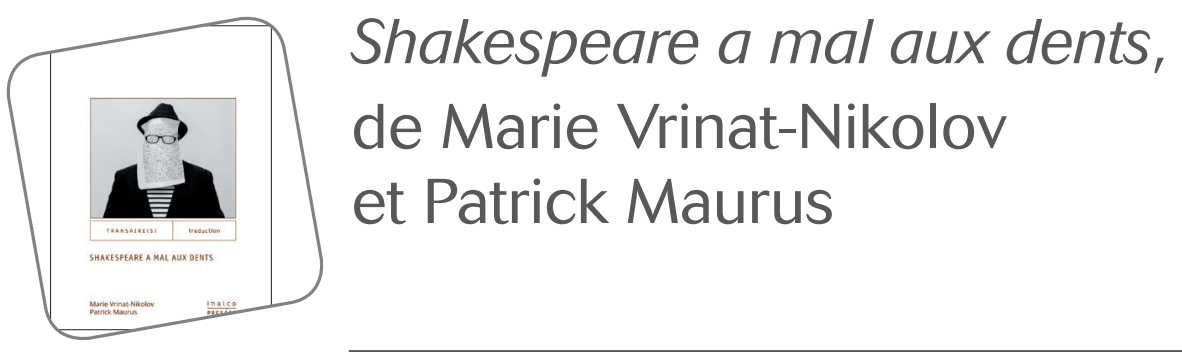

Marie-Céline Georg

Marie Vrinat-Nikolov enseigne la langue et la littérature bulgares et est responsable du master de traduction littéraire à I'Inalco. Patrick Maurus est professeur émérite de coréen à l'Inalco, traducteur et directeur de collection chez Actes Sud. Ensemble, ils interrogent l'acte de traduire en littérature. Étant donné leur activité plurielle, ils connaissent aussi bien les aspects pratiques que théoriques de la traduction littéraire. À partir de quelques questions essentielles - qui, quoi, quand, où? -, ils décortiquent les différentes conceptions actuelles de la traduction, la chaîne éditoriale et économique au cœur de laquelle elle tente de se faire une place, les champs dans lesquels elle se pratique ou se théorise. À chaque étape, ils démontent sans pitié un certain nombre de mythes et de clichés - le traducteur serviteur, invisible ou traître, l'intraduisibilité, la «bonne» langue française, la perfection de l'original...

Pour les auteurs, l'acte de traduire ne peut s'envisager isolément. Ils font exploser les limites de la traduction en démontrant qu'elle ne se cantonne pas à l'aspect linguistique, qui fait l'exclusivité de certaines réflexions théoriques: on ne traduit pas "des langues», mais des textes dont le son, la forme, le rythme font partie intégrante. Ils s'interrogent sur la pertinence de toutes les théories qui tendent à vouloir faire 
entrer la traduction dans la norme étroite et réductrice d'une "Ainsi Nommée Littérature», faisant disparaître une grande partie des caractéristiques du texte d'origine, en particulier sa nature étrangère. C'est un problème crucial surtout quand on examine des textes écrits/traduits de langues dont le système graphique et les références culturelles diffèrent largement du français. S'appuyant sur la notion d'historicité introduite par Henri Meschonnic, ils expliquent que l'acte de traduire est nécessairement pris dans une trame complexe d'intervenants et de facteurs circonstanciels qui exercent une influence sur le traducteur et le résultat de son travail. Ils appliquent une approche sociocritique à leur analyse en définissant chaque aspect d'une triade trace/indice/valeur, pour démontrer comment le texte s'inclut dans toute cette trame de sens, de références et d'influences.

Ils proposent ainsi, sans pour autant vouloir l'imposer comme un dogme, une vision renouvelée de la traduction et du traducteur: "le traduire» est un acte pluriel, réinventé à chaque instant devant chaque texte par un «traduisant» qui intègre tous les aspects inscrivant ce texte et son travail dans un contexte social, historique et culturel. Ce faisant, ils militent également pour la visibilité du traducteur au sens où, à leur avis, il ne faut pas gommer l'origine d'un texte, qui fait partie intégrante de sa valeur, c'est-à-dire ne pas voiler la nature traduite d'un texte.

Les auteurs utilisent des images très parlantes pour faire passer l'idée que la traduction doit intégrer les multiples facteurs d'un texte: "Le traduisant est celui qui sait quand Shakespeare avait bu une coupe de vin ou quand il avait mal aux dents.»

Tous ces facteurs peuvent sembler multiplier les contraintes sur le traducteur, mais ce sont aussi des pistes de libération qui lui permettent de légitimer sa réflexion et ses choix, même quand ils s'écartent des canons de la littérature conventionnelle, parce qu'ils correspondent à une cohérence globale qui émane du texte même.

Certes, ce livre est circonscrit au domaine de la traduction littéraire: l'exclusion de la non-fiction et de toute autre forme de traduction non éditoriale peut sembler radicale. II offre néanmoins un panorama intéressant du métier qui plaide pour plus de perméabilité entre théorie et pratique. Malgré 
la densité de l'ouvrage, les nombreux exemples concrets qui font la part belle à des langues dites «rares» et les analogies avec la musique ou d'autres arts illustrent clairement les différents arguments des auteurs.

Marie Vrinat-Nikolov et Patrick Maurus, Shakespeare a mal aux dents, Collection TransAireS, Paris, Presses de I'Inalco, 2018, https:// books.openedition.org/pressesinalco/1512? lang = fr 